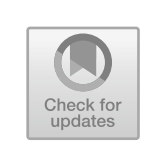

\title{
Introduction: The Need for New Thinking
}

Writing in The New York Times during the midst of the Covid-19 crisis, Thomas Friedman said that, from the time the Coronavirus appeared onward, "There is the world B.C.-Before Corona-and the world A.C.-After Corona." This is definitely an After Corona book, and I am certain there will be many others. Most thinking people recognize the Covid-19 crisis as a turning point in our human affairs, and hope we will seize it as an opportunity for a fresh start. But the book I am offering here is different. I really believe it should be the starting point for all others.

Quantum scientist David Bohm said, "All the problems of the world are problems of thought. If we want to change the world, we need to change the way we think." If we are really going to create a better, wiser, and more sustainable post-Covid world, we will need to think differently, and to organize differently. We need to change the mindset that determines how we see and act in the world. As Peter Diamandis \& Steven Kotler make clear in their eye-opening book The Future is Faster Than You Think, the human brain evolved for thousands of years to think about and adapt to an environment that was local, linear, and largely stable, and we used it to build organizations, social institutions, and government agencies that now find it difficult to cope with today's uncertainty, complexity, rapid change, and global interconnectivity. To build more relevant and resilient ones, we need to update the thinking that created the old ones.

Neuroscience now teaches us that our brains are "plastic," and that we can "rewire" them. The way that we experience and think about our

(C) The Author(s) 2022

D. Zohar, Zero Distance, https://doi.org/10.1007/978-981-16-7849-3_1 
surroundings and relationships actually reinforces or alters the complex system of neural connections that shape that thought and experience. Change the way we think, we change the way we do all future thinking, and what we do with it. This book offers a radically new, total framework, for thinking differently (about everything!), and thus for organizing differently. And it offers a radically new organizational model for implementing this new thinking in companies and other social systems.

\section{THIS Book}

This book about a new paradigm in management thinking and a new, practical model for implementing it in our personal and working lives, in our companies, in our communities and nations, and in a sustainable global order. It will offer an understanding of why and how "thinking-asusual" is failing both business and political leaders in these new times, and it will advocate new thinking and new management practices that are so radically new that they turn everything we have taken for granted inside out and upside down. I call this new management model "Quantum Management," because it is rooted in the new paradigm bequeathed to us by quantum physics and its younger sibling, complexity science.

The new organizational model featured here originated as a business model designed and implemented in 2012 by Haier, China. Haier, still largely a domestic appliances company based in Qingdao, is one of China's largest and most successful global companies and the world's largest supplier of domestic appliances. In January 2016, Haier acquired (one of its many global acquisitions) the stagnating GE Appliances that the parent GE wanted to off-load, implemented its own business model there, and has turned the company into a great success, even by the usual standards of profitability, share-holder value, company ranking, and increased market share. The story of how GEA has been turned around with the Haier business model is particularly important for American readers because it proves that a very radical new model conceived by a Chinese company can work in America.

Thus, this is not a book about Haier itself which, though one of China's most successful global companies, need be of no more interest to English-speaking readers than any other successful Chinese company. It is the Haier business model that moves Gary Hamel and Michele Zanini to describe Haier as "arguably the world's most creatively managed company," in their book, Humanocracy, and its CEO Zhang Ruimin as 
one of the world's most innovative leaders. It is the Haier business model that is attracting so much attention among business leaders and leading business schools in Asia, Europe, and even America. It is the Haier business model, that is the subject of so many case studies and so many featured articles in the business press-most recently an article by Gary Hamel in the December 2018 issue of The Harvard Business Review. It is the Haier business model that brings 10,000 visitors a year, many of them American business leaders and academics, to the company headquarters in Qingdao. And it is the Haier business model that I will argue in this book gives us a practical model for implementing much needed new thinking, not just in business but new thinking about individual people and employees, new models for social and political organization, and a new model offering a vision for a very different kind of global order.

This book is also about the management theory that Haier Chairman \& CEO Zhang Ruimin credits with largely inspiring his own thinking when designing the company's new business model. This is my own Quantum Management Theory, developed over the past forty years as part of my broad project to tease out and articulate a new paradigm (in the full Kubnian sense of that word) for all thinking about everything, modeled on the defining principles and philosophy found within quantum physics. I base my argument on the fact that it was the philosophy and principles of Newton's seventeenth-century mechanistic physics that gave rise to the modern, Western paradigm and its embodiment in Taylorism, the management theory that still dominates nearly all business thinking and practice today. My argument is that the paradigm shift in physics heralds and defines a broader paradigm shift in the way we experience and think about everything-including management.

I have published three previous books within which Quantum Management Theory has evolved, but they were just books about a theory, and though many business leaders found it attractive, they didn't see how it could actually work for them. What is different about this book is that Haier, followed by Roche India \& GE Appliances in America, and the American Army's own Special Operations Task Force (the "green berets"), has now embedded the theory in a practical business model, and given it life by implementing it in the structure, practice, and culture of the company. Haier's Zhang Ruimin had the genius and the courage to turn what was only a theory into an actual, practical business model 
that has worked. And, thus, I can present here for the first time a theory that both sets out the framework for a new, quantum paradigm, and backs this up with some solid case studies of real organizations that have implemented the theory with demonstrable success.

\section{The Haier Business Model}

I shall, of course, describe the Haier model in great detail in Chapter 4 of this book. Condensed here to just a few short words, Zhang Ruimin surrendered all power at the top of the previous Haier hierarchy. $\mathrm{He}$ did away with all middle management, and turned many of them into CEOs of their own, independent, and self-organizing microenterprises. All powers of decision making, hiring, \& remuneration were passed to these microenterprise heads. In every sense, each microenterprise is a company in its own right, working directly with its own customers to innovate and produce its own products in response to those customers' declared needs and preferences. Microenterprise teams are paid directly by their customers, not by Haier itself, and they keep most of their own profits, passing back to Haier a proportion to pay for the larger company service platforms that provide the scale of backup service only available to a larger company. These service platforms are run by senior management. All that Zhang Ruimin himself now does is provide the vision, the inspiration, the resources, and the personal character traits that "glue" the whole operation together. Today there are nearly 4000 customer-facing microenterprises, each acting as an innovative start-up, and Haier itself is described as "a company of companies," providing the combined benefits of large company resources together with the innovative capacity of small start-ups.

That was a brief description of the structural aspects of the Haier transformation. There are also crucial, defining cultural aspects. Now that "every employee is a CEO" (a company motto), the microenterprise teams are as highly motivated and committed to the success of the team as any business people who own their own company. The usual emphasis on products has been replaced with an emphasis on process and service, getting high-quality products to customers with whom each microenterprise is in direct, interactive contact. The most important company motto is, "At Haier, the customer is the boss." And, perhaps most radically, Haier has redefined the metrics for success. Short-term shareholder value and market share have been replaced as indicators by growing numbers of 
loyal customers who constantly return for more products. Following this model, Haier was recently listed on the Fortune 500.

In both Chapters 4 and 15, as I offer detailed descriptions of the Haier model, its infrastructures, processes, and practices, I will make clear how each of these is an expression of Quantum Management principles in action.

\section{My Own Involvement with Haier}

In October 2014, I received an email from Haier Chairman Zhang Ruimin. He told me that he admired my work and that my ideas about Quantum Management had influenced much of his thinking when designing Haier's new business model and company transformation program. He invited me to the company headquarters in Qingdao to meet with him personally, to meet his senior leadership team, and to give a lecture to the top 250 people in management. During a 2 hour personal meeting, he asked me many questions about quantum physics, explained to me specific ways in which he felt his new business model was putting quantum principles into practice, and shared his enthusiasm for similarities he saw between my own quantum work and the thinking of traditional Chinese philosophy, especially Taoism, which also inspired his business thinking. After our conversation, he invited me to his private office and pointed to a row of books in the Mandarin language, saying, "These are all your books." Unknown to me, he had been ordering private Mandarin translations of all my books going back as far as The Quantum Self, "because they were so helpful with my developing vision for Haier." I was stunned! And somehow awkwardly embarrassed, not knowing what to say. Before receiving Mr. Zhang's email invitation to visit Qingdao, I had only heard vague things about Haier, as "an interesting company."

For the past 5 years, I have continued visiting Haier two or three times a year, always at Zhang Ruimin's invitation and always including a long personal conversation with him. We discuss physics, philosophy (both East \& West), global politics, our favorite authors \& ideas, the role that business might play in changing the world for the better. An accomplished intellectual in his own right, Zhang Ruimin is fondly known throughout China as, "The philosopher CEO."

Each of my many visits to Haier also always involved conversations and short "mentoring" seminars with the various platform leaders and many of the microenterprise teams. I have always worked particularly closely 
with the Strategy Platform and the Culture Platform. In September 2018, I was awarded the $\$ 200,000$ Haier RenDanHeyi Medal "For Academic Contribution to the Haier Business Model." My fellow winners were Gary Hamel \& Rosbeth Moss-Kantor, both of whom have also had a long relationship with Haier.

Shortly after my most recent book, The Quantum Leader, became a Business Best Seller in its Mandarin translation (2016), and I was named "China's Top Innovation Management Thinker of 2018," by the highly respected Tsinghua Business Review, I met with Mr. Zhang again. He told me, "Everyone in business is talking about your book. Quantum Management is now China's new Big Idea." He was pleased about this, but also deeply concerned that the book's popularity was making "everyone want to jump on board, and most of them don't know what they are talking about." He worried that this rush of unqualified copycats would cheapen \& discredit the idea of Quantum Management. He then suggested that I write "the Bible of Quantum Management to keep the idea pure," and recommended the five-part structure described in this outline, "to include the themes of all your major books and applying them specifically to business \& management." Hence the book outlined here. Its title, Zero Distance, is both another name for the Haier business model and a defining principle in quantum physics.

\section{Summary of the Book's Argument ANd Development}

At the 2019 Davos Economic Forum, many of the world's most powerful business leaders gathered there, when interviewed by the media, described an air of pessimism prevailing in their meetings and conversations. It was generally recognized, they said, that that the global community is facing very serious, in some cases existential, problems, but they were not able to think of workable solutions. The problems discussed included climate change, of course, the increased threat of nuclear conflict in an unstable world, mass migration, the prospect of massive unemployment resulting from ever new technology, populism, identity, inequality, and the economic uncertainty associated with some, or all, of these. And for the business leaders of course, there were the familiar problems associated with today's uncertainty, rapid change, and adjustments to globalization. Big problems indeed! And added to all this, we now have Covid!

My view is that the real problem leaving these leaders unable to find solutions is that the thinking they have always used when faced with 
problems or challenges is not equipped to deal with these very twentyfirst-century ones. Indeed, their accustomed thinking, and the world it created, caused most of these problems. And neither does that same outdated thinking allow them to turn many of the problems into opportunities. It seems obvious to me that none of us can solve the problems or seize the many opportunities of life in the twenty-first century with thinking designed in the seventeenth century to cope with the problems and opportunities of The Industrial Age that followed. We need to "rewire our brains"!

And that is what this book is promising to offer: an understanding of why and how thinking-as-usual is failing both business and political leaders, and a description of a new kind of thinking that is so radically new that it will turn everything they have taken for granted inside out and upside down. I will argue that a paradigm shift that began in the early years of the twentieth century has now come fully into play in the twenty-first, that this paradigm shift is revolutionary, and that it calls for new thinking in every aspect of human affairs. This new thinking, when applied to business, will demand not only that leaders change how they manage, how they make decisions, how much power they have, and their very role as leaders, but that they will have to create whole new structures and infrastructures, whole new meanings and purposes, for the organizations, or social systems they lead.

As Zhang Ruimin commented on what is required, "You simply have to forget everything you thought was true, and start from scratch." Both Zhang's leadership philosophy, and the business model he conceived to guide his radical company transformation program, will be the central characters and role models in this book. So readers here will not have to start entirely from scratch! They will have the example of Zhang Ruimin and other leaders who have successfully followed that example to guide them, and I will provide the essential elements of the disruptive thinking they and I will argue is needed to thrive as leaders in the twenty-first century-both to solve its problems and to seize its opportunities. But much of the reinvention required will be neither quick nor easy. It requires deep change, and as any leadership mentor worth the high hourly fee he or she is charging to advise their clients will warn, deep change takes time. I would add, it also takes commitment and courage. The pioneering leaders I write about in this book took enormous risks, with both their companies and their own careers, and they told me they did so because, "I was deeply convinced that it was right. I had to do it." 
I call the new thinking I shall advocate so strongly "quantum thinking," the leaders who practice it "quantum leaders," and the management model embedded in the successful transformation programs described in what follows, examples of Quantum Management Theoryin action! And unlike so many, chiefly New Age, authors, advertisers, and countless others, I use the word "quantum" as an actual reference to quantum physics!! I see quantum physics as the origin of and basis for the new paradigm that now calls for new thinking about everything in twenty-first-century life. While quantum physics itself, as practiced in the laboratory and originally conceived as describing the strange microuniverse within the atom, clearly has nothing to say about management*, the ideas, categories of thought, underlying principles, and philosophy that underpin it as pure physics, clearly are of wider paradigmatic significance. As were the principles of Newton's physics when they were published in the seventeenth century, and thus adopted in their own work by every major thinker in every field whose ideas for the following 300 years created and defined the Modern Age. Thus Quantum Management Theory is inspired by, and draws its own principles and philosophy from, those that define quantum physics itself. ${ }^{1}$

The paradigm that arose from Newton's seventeenth-century physics was adapted as a "scientific management theory" by the Scottish engineer Frederick Taylor in the early twentieth century. "Taylorism" as it became known, was universally adopted by global business. Every management theory and every management practice, every management strategy and every management decision since, has borne the mark of Taylorism. And that was right while businessmen were operating in the simple, stable, predictable, and controllable world of machines and their technology.

But the Industrial Age is past, and so are the industrial machines and the mechanistic certainties that allowed business to generate great wealth and draw successful management models from them. The new technology of the twenty-first century is digital, and our new century is frequently called the Age of the Internet. Haier's Zhang Ruimin more correctly calls it "The Quantum Age." This is because all the new technology now forming the basis of twenty-first-century economic and scientific

${ }^{1}$ It is important to note that the living quantum systems that complexity scientists call "complex adaptive systems" are directly relevant to understanding things like companies and cities, and thus are described at length in this book. They are the bedrock science upon which Quantum Management is based. 
development is quantum technology. The digital revolution itself was made possible by the silicon chip. Every digital tool or service we use today, from our computers, smart phones, smart appliances, video gaming machines, and the internet itself, was made possible by the arrival of the silicon chip. And the silicon chip itself was made possible by knowledge gained with quantum physics. As are any devices using laser technology or technologies relying on solid state systems like superfluids and superconductors. These include the new "quantum computers" that are causing so much excitement.

The revolutionary quantum technologies of the Quantum Age both offer new opportunities and create new problems, and that is why we need "quantum thinking" to seize the opportunities and solve the problems. Leaders of social systems and business organizations need to understand the logic behind the new systems and organizations they now lead, both how it is different from the old Newtonian logic of the Industrial Age, and how being able to use the new quantum logic can serve their needs and meet their challenges today. And that is why I offer Quantum Management Theory, and the thinking it presents, as a necessary leadership philosophy to guide all twenty-first-century leaders.

Theories in science must be tested by experiment before they can be accepted as valid. It is the same with new theories in management. This book therefore offers detailed case studies of three large companies whose leaders took the risk of testing Quantum Management Theory by fully implementing it as a business model to guide large-scale company transformation programs. These companies are Haier China, Roche India, and GE Appliances in America. Their success stories provide "experimental" validation of the theory and a guide for others to follow.

Haier was the first large, global company to pioneer the implementation of Quantum Management Theory, and Haier Chairman Zhang Ruimin's RenDanHeyi business model was the first to present these ideas in the form of a practical business model. RenDanHeyi is Quantum Management in practice, and that is why it interests me. Both Roche India and GE Appliances took their lead from the Haier model and adapted it for their own transformation programs, and the American Army's Special Operations Task Force, perhaps independently, introduced an identical transformation adapted for military purposes. Therefore, RenDanHeyi and its implementation at Haier form the template I describe in this book for other companies and organizations to follow. I also go further, and argue that Haier's RenDanHeyi business model has applications as a social 
and political model that could address challenges facing leaders in government and public service. And in Part II of the book, I present applications of RenDanHeyi that I believe could help individual people adjust to the new global realities and working conditions that are causing so much fear and confusion in our personal lives.

Zero Distance is not "just another business book," and Quantum Management Theory not "just another business theory." It is the first new organizational theory to offer an overarching theoretical framework for fundamental change in the way we think about management-a new management paradigm grounded in science and the new scientific understanding of organizational systems dynamics. Thus it offers the first comprebensive understanding of why we face the problems that we do, why our familiar solutions are not working, and the fundamentally new thinking we need to adopt if we are to find better solutions and more creative responses to the many new problems \& opportunities presented by twenty-first-century realities.

Many piecemeal stabs have been made at suggesting new solutions for business - "the flexible organization," "agile organizations," "dynamic capabilities," "conscious capitalism," "humanocracy," "authentic leadership," "sapient leadership," "holocracy," "the Teal organization," etc. And several experiments are being made to address various problems in society. All of these are good ideas, but piecemeal solutions cannot be effective unless part of a comprehensive, larger framework that explains why there are problems that need new solutions and why the solutions being offered are good ones. Experiments are blind if not embedded in a comprehensive understanding of why they are being tried. Thus a senior partner in one global consultancy admitted to me after being introduced to Quantum Management Theory, "I see now that everything we have been doing with clients is shallow and piecemeal, and that we have been wasting our own and everyone else's time." Indeed, Quantum Management Theory is best understood as a meta-theory, within which many new management ideas can find their home.

The paradigm shift reflected in Quantum Management is so fundamental, and so relevant to every aspect of our business and social lives, that no one book, nor no one thinker, can tease out all the opportunities offered in all the fields of thought and action where it might be implemented, especially not one now in her mid-seventies. There are so many more applications of responsible, informed, quantum thinking! I can only hope that others will follow my lead, and write those books. 


\section{STRUCture of This Book}

I want to explain briefly here why I am writing the book in five parts and covering the topics that I do. Part I, Building Blocks, is necessary to equip readers with the understanding they need to make best use of the arguments and examples that follow. Parts II through V, devoted in sequence to The Quantum Self, The Quantum Leader, The Quantum Organization, and The Quantum Society (including a Quantum Global Order) represent my conviction that we don't live our lives in isolated silos of experience, and the insight from quantum physics that, "Everything is connected to everything." This supports my argument that business, its philosophy, values, culture, priorities, and decisions, is the business of everyone because it impacts on every aspect of everyone's life. Any business (or other) leader is also of course a personal individual with a private life. The quality and nature of that private life are affected by the decisions of business leaders and, in a quantum organization, the character of that personal individual is of central importance to the quality and efficacy of his/her leadership. And, of course, every leader is also a citizen, local, national, and global. And both the nature and quality of society, and the survival of our fragile planet and its global community are directly affected by the personal character and personal/professional values, and thus consequences of his/her leadership decisions. Therefore, though presented in five parts, each part of the book has implications for and further develops the theme of every other part. 
Open Access This chapter is licensed under the terms of the Creative Commons Attribution-NonCommercial-NoDerivatives 4.0 International License (http:// creativecommons.org/licenses/by-nc-nd/4.0/), which permits any noncommercial use, sharing, distribution and reproduction in any medium or format, as long as you give appropriate credit to the original author(s) and the source, provide a link to the Creative Commons license and indicate if you modified the licensed material. You do not have permission under this license to share adapted material derived from this chapter or parts of it.

The images or other third party material in this chapter are included in the chapter's Creative Commons license, unless indicated otherwise in a credit line to the material. If material is not included in the chapter's Creative Commons license and your intended use is not permitted by statutory regulation or exceeds the permitted use, you will need to obtain permission directly from the copyright holder.

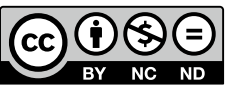

